\title{
As mulheres (in)visíveis na Arte Renascentista
}

\author{
Renata Lima Cremasco ${ }^{7}$ \\ DOI 10.20396/eha.vil4.3476
}

Na segunda metade do século XVI, duas mulheres conquistaram seu espaço e foram protagonistas de sua própria arte. Sofonisba Anguissola e Lavinia Fontana, que até hoje têm seus nomes e notáveis trabalhos pouco difundidos, se opuseram à conjuntura renascentista na qual a mulher era excluída e relativizada em sua capacidade intelectual e conseguiram desenvolver a atividade artística como profissionais.

Em períodos anteriores ao Renascimento, as mulheres tinham variadas formas de atuação em diferentes sociedades. A visão de que a dominação masculina é universal vêm sendo contestada por antropólogos e historiadores que observaram as relações de submissão feminina ao longo da história. Povos como Gauleses e Iroqueses, por exemplo, eram constituídos pela participação da mulher nas mesmas funções que os homens ocupavam: nas guerras, trabalhos no campo e tomadas de decisões de interesse conjunto.

Desmitificando a ideia de que a sujeição da mulher seja um destino irrevogável, a histórico e universal, levanta-se a experiencia da relação entre os sexos existentes na Gália e na Cermânia. Eram sociedades tribais, cujo regime comunitário designava às mulheres em espaço de atuação semelhante ao dos homens. ${ }^{2}$

A posição da mulher em antigas sociedades foi diversa e, em muitas, a figura feminina teve status relativamente significativo, participando de forma ativa em suas comunidades, ao lado dos homens nas incumbências. Segundo Lerner³ , há estudos que apontam que nas sociedades do período Neolítico e na Idade do Bronze as mulheres eram enaltecidas e provavelmente, tinham algum poder os quais indícios sugerem que eram cultuadas como deusas da fertilidade.

No início da Idade Média, é possível observar a atuação de mulheres na sociedade, exercendo funções como carpintaria e serralharia que ficaram acessíveis a elas uma vez que havia grande afastamento dos homens que participavam de guerras e dedicavam-se à longas viagens para con-

\footnotetext{
1 Aluna especial da disciplina Montagem, desmontagem e remontagem em Georges Didi-Huberman: Quando as imagens tomam posição da Escola de Artes, Ciências e Humanidades - Universidade de São Paulo.

2 ALVES, Branca M.; PITANGUY, Jacqueline. O que é Feminismo. São Paulo: Abril Cultural, Brasiliense, 1985, p. 15.

3 LERNER, Cerda. A criação do patriarcado: história da opressão das mulheres pelos homens. São Paulo: Cultrix, 2019.
} 
quistas de territórios ${ }^{4}$. Nesse período também participavam de atividades voltadas para o comércio junto aos seus maridos bem como na produção de alimentos e tecelagem que eram exercidos na esfera doméstica.

Comparando a posição da mulher à Idade Média, no Renascimento observamos declínio em sua atuação na sociedade, pois a reincorporação da Legislação Romana provocou um recuo no (pouco) espaço participativo que a mulher tinha na esfera pública. A formação dos estados nacionais e a centralização do poder, contribuiu para circunscrever seu direito de propriedade e sucessão adquiridos na Idade Média bem como administrar seu próprio negócio 5 .

O lugar que hoje se denomina a Itália (uma vez que o país se unificou apenas no século XIX), vivia naquele período o seu apogeu comercial, sendo um dos principais centros econômicos da Europa e dando início ao pré-capitalismo. Isto possibilitou que esta região ficasse em vantagem econômica em relação às demais cidades, devido à sua política mercantilista. Este desenvolvimento econômico estruturou a futura sociedade Italiana em uma vertente com atitudes liberais que abriram espaço para a expansão cultural, como expõe Peter Burke "A grande regeneração da arte e das ideias começou em Itália e mais tarde as novas posturas e as novas formas artísticas espelharam-se pelo resto da Europa."

Nessa conjuntura, os renascentistas almejavam o resgate da cultura clássica Greco-Romana nas artes e na literatura, modificando traços particulares da arte em relação à Idade Média. O exercício da arte foi transformado, adquirindo uma nova identidade em que o artista também sofreu alterações, ganhando uma nova posição social, visto que para o fazer artístico são necessários meios de treinamento para o constante aperfeiçoamento das técnicas. A transformação da figura artística na Renascença Italiana possibilitou que a profissão de artista ganhasse a reputação de intelectualizada, uma vez que os artistas deveriam ter educação liberal nas artes, com uma ênfase especial na matemática e nas leis de perspectivas e conhecimento na arte antiga

A visão da mulher como desqualificada para atuar na vida intelectual, era reforçada por autores e filósofos que compartilhavam suas convicções a respeito da figura feminina. O filósofo Léon Battista Alberti afirmava que as virtudes das mulheres eram castidade e maternidade e suas atribuições destinavam-se apenas ao mundo privado. Alberti ainda cita em Della famiglia que a passividade também deveria ser uma característica feminina, bem como deveria ser pura e fisicamente

\footnotetext{
4 ALVES; PITANGUY, op. cit., 1985.

5 ALVES; PITANGUY, 1985.

6 BURKE, Peter. O Renascimento. $1^{\text {a }}$ ed. Lisboa: Edições Texto \& Grafia, 2008, p. 10.
} 
atrativa

O desenvolvimento no período Renascentista permitiu uma nova viabilidade para os homens, mas as mulheres tiveram seus poderes afetados, vivendo com menos do que tiveram no início do feudalismo. A historiadora americana Joan Kelly-Gadol em seu artigo "As mulheres tiveram um Renascimento?" (tradução livre), explana de forma esclarecedora o cenário da mulher:

Mas o fato inicial é que as mulheres como um grupo, especialmente entre as classes que dominavam a elite urbana italiana, experimentaram uma contração das opções sociais e pessoais que os homens de suas classes não experimentaram tão acentuadamente, como foi o caso da burguesia e da nobreza. ${ }^{7}$

No início do século XVI, o diplomata Italiano Baldassare Castiglione escreveu o livro O cortesão, um manual de etiqueta, publicado em 1528. O livro, I/ Cortegiano, teve mais de trinta edições espalhadas pela Itália, Espanha, Inglaterra e França e tornou-se prestigiado na sociedade. Castiglione expõe que os mesmos atributos que eram necessários para um membro masculino da corte, também deveriam ser necessários às mulheres, como por exemplo: habilidades na pintura, tocar instrumentos, cantar e escrever poesias ${ }^{8}$. Esses ideais de comportamento não eram novos já que na Idade Média, era possível encontrar em manuais esses mesmos pensamentos, entretanto, com a técnica de impressão, essas ideias foram espalhadas com mais eficácia e rapidez do que na Idade Média.

O cortesão foi bastante influente entre as famílias nobres, proporcionando educação às muIheres, como podemos encontrar em Women Artists -1550-1950, "Ele tornou apropriado e até mesmo louvável, que as mulheres se envolvessem em uma ampla gama de atividades artísticas, musical e literária". ${ }^{9}$ Sofonisba Anguissola, suas irmãs e o único irmão, Asdrubale, tiveram a educação baseada no manual de Castiglione: foram instruídas a ler em Latim, tocar instrumentos e pintar.

Nascida em 1530 em Cremona, era a mais velha de seis irmãs e um irmão de uma família que pertencia a uma pequena aristocracia cujo pai, Almicare Anguissola, os treinou para serem excepcionalmente realizados. Sofonisba e sua irmã Elena, estudaram no ateliê do pintor Bernardino Campi entre 1550 e 1559. Elena se tornou monja e entrou para o convento, mas Sofonisba, encorajada por seu pai, continuou se dedicando a pintura.

O talento de Sofonisba foi destacado e seu pai não mediu esforços para promovê-la e

\footnotetext{
7 KELLY-GADOL, Joan. Did Women Have a Renaissance?, 1977, p. 139, tradução nossa.

8 CHADWICK, Whitney. Women, Art, and Society. $5^{\mathrm{a}}$ ed. Nova York: Thames \& Hudson world of art, 2012.

9 HARRIS, Ann Sutherland; NOCHLIN, Linda. Women Artists: 1550-1950. $3^{\text {a }}$ ed. Nova York: Knopf, 1984, p.24, tradução nossa.
} 
na tentativa de difundir o trabalho da filha mais velha, Almicare por diversas vezes levou seus desenhos à Roma. Chegou a escrever uma carta para Michelangelo e junto a ela enviou um desenho de Sofonisba (figura 1), em resposta, Michelangelo propôs que Sofonisba enviasse outro desenho (figura 2) para que ele pudesse contestar sua habilidade na captura da expressão humana - o que Sofonisba executou com sucesso ${ }^{10}$.

Após ficar muito conhecida entre as famílias nobres, em 1559, aos 27 anos, partiu para a Espanha como convidada do Rei Felipe II. Como mulher, não era permitido que fosse reconhecida oficialmente como pintora da corte, portanto, seu título era de dama de companhia da Rainha Isabel de Valois. Em pouco tempo na corte, Sofonisba ganhou a confiança dos Reis e teve permissão para retratá-los, bem como as infantas (figura 3).

Permaneceu na corte espanhola por aproximadamente dez anos, casou-se por duas vezes e passou os últimos anos de vida dividindo-se entre Palermo e Cénova. Em 1624 recebeu a visita do então jovem pintor flamengo Van Dyck, que registrou o encontro em seu diário de viagem (figura 4) e a quem Sofonisba com mais de 90 anos, porém muito lúcida, deu vários conselhos sobre pintu$\mathrm{ra}^{11}$. A passagem de Sofonisba Anguissola pela corte de Felipe II, abriu as portas para muitas outras mulheres que não encontraram suporte em academias ou patrocínio cívico entre os séculos XVII e XVIII. Seu trabalho influenciou diretamente o de Lavinia Fontana.

Treinada por seu pai, o pintor Prospero Fontana, Lavinia iniciou sua atividade como pintora retratando famílias nobres da cidade de Bolonha. Suas primeiras pinturas foram doadas ou vendidas a preço muito baixo como estratégia de impulsionar sua publicidade, tática que viabilizou seu trabalho, promovendo sua reputação como como retratista (figura 5).

Prospero arranjou o casamento de Lavinia com seu aluno Gian Paolo Zappi na condição que o casal vivesse com ele e Lavinia continuasse trabalhando e ajudando nas despesas da casa. Zappi, se tornou o gerente de negócios de Lavinia, apoiando-a e promovendo seu trabalho ${ }^{12}$. Após a morte de seu pai, em 1563, Lavinia e sua família se mudaram para Roma a pedido do Papa Clemente VIII para ser pintora oficinal do papado onde executou obras religiosas e históricas, muitas delas grandes retábulos (figura 6).

Apesar da mulher ser impedida em ter acesso ao estudo do nu para desenvolver sua pintura, Lavinia superou esse obstáculo ao pintar Minerva Dressing em 1612/1613 que de acordo com pes-

\footnotetext{
10 HELLER, Nancy. Women Artists. $3^{\text {a }}$ ed. Nova York: Abbeville Press, 1997.

11 Ibidem, 1997.

12 CHADWICK, 2012.
} 


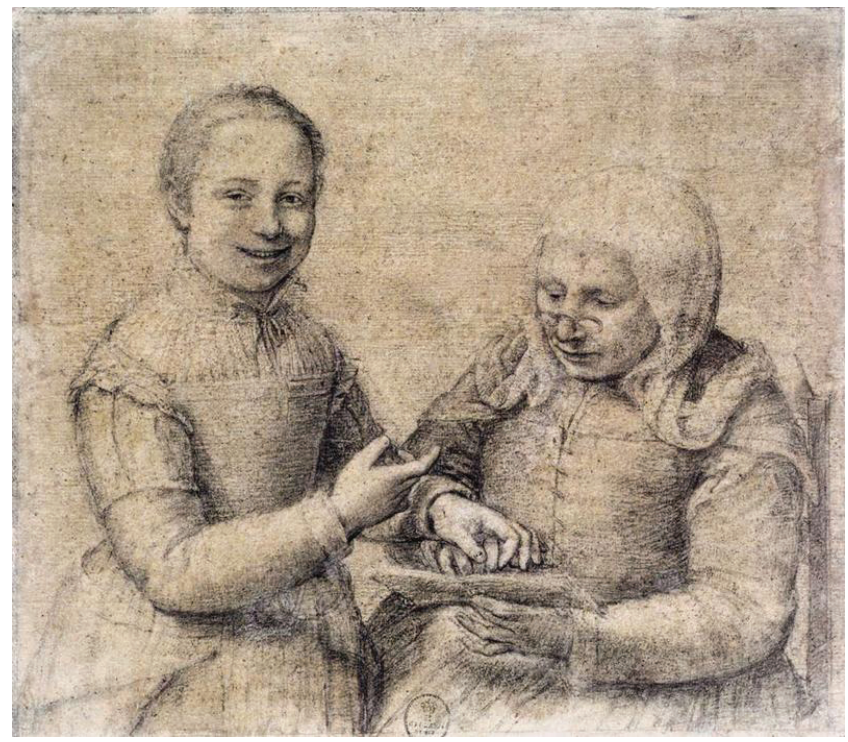

[Figura 01] Sofonisba Anguissola. Old Woman Studying the Alphabet with a Laughing Girl, 1550.

$301 \times 305$ mm - Galleria degli Uffizi, Florence.

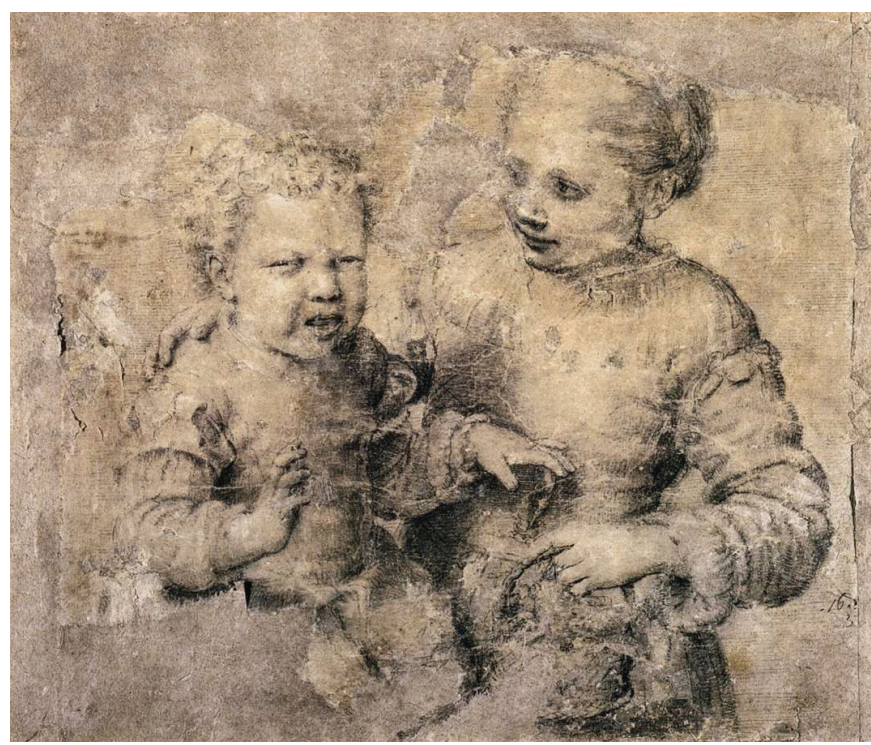

[Figura 02] Sofonisba Anguissola. Asdrubale Bitten by a Crawfish, 1554.

333×385 - Museo Nazionale di Capodimonte, Naples.

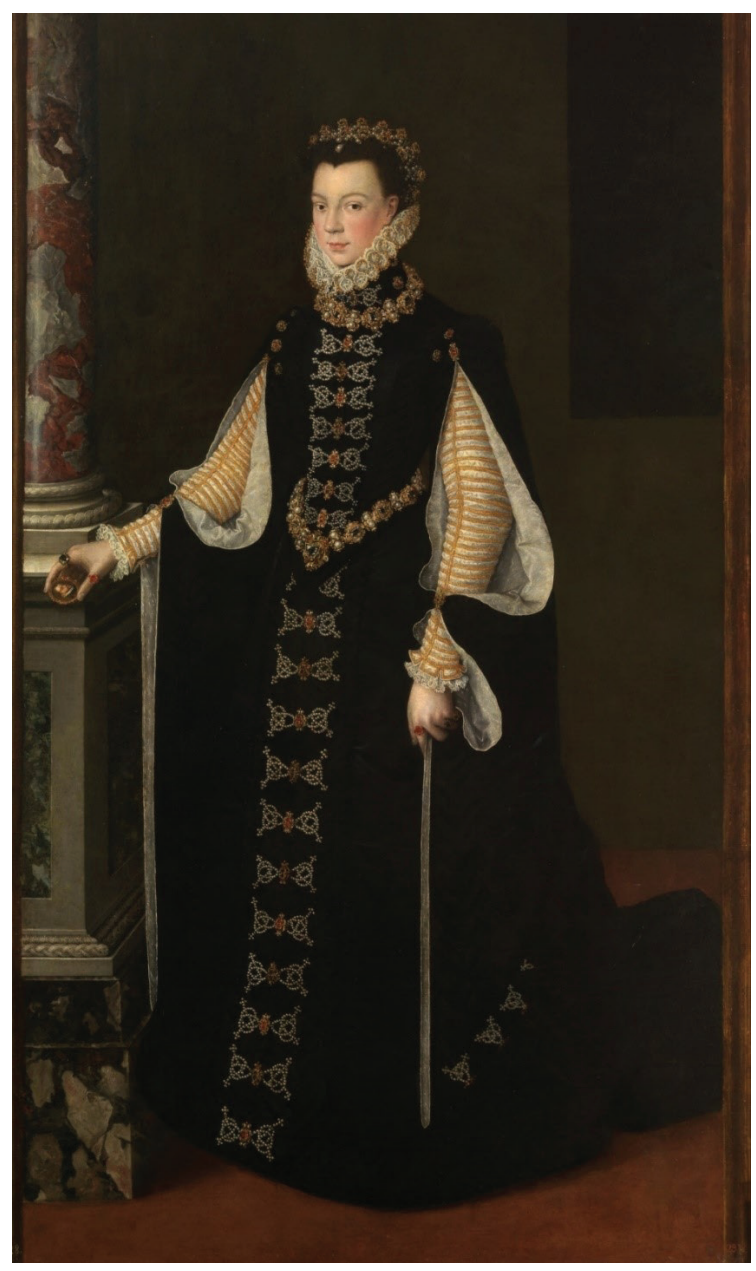

[Figura 03] Sofonisba Anguissola. Isabel de Valois sosteniendo un retrato de Felipe II, 1561-1565.

$206 \times 123 \mathrm{~cm}$, Oil on canvas - Museo del Prado, Madrid.

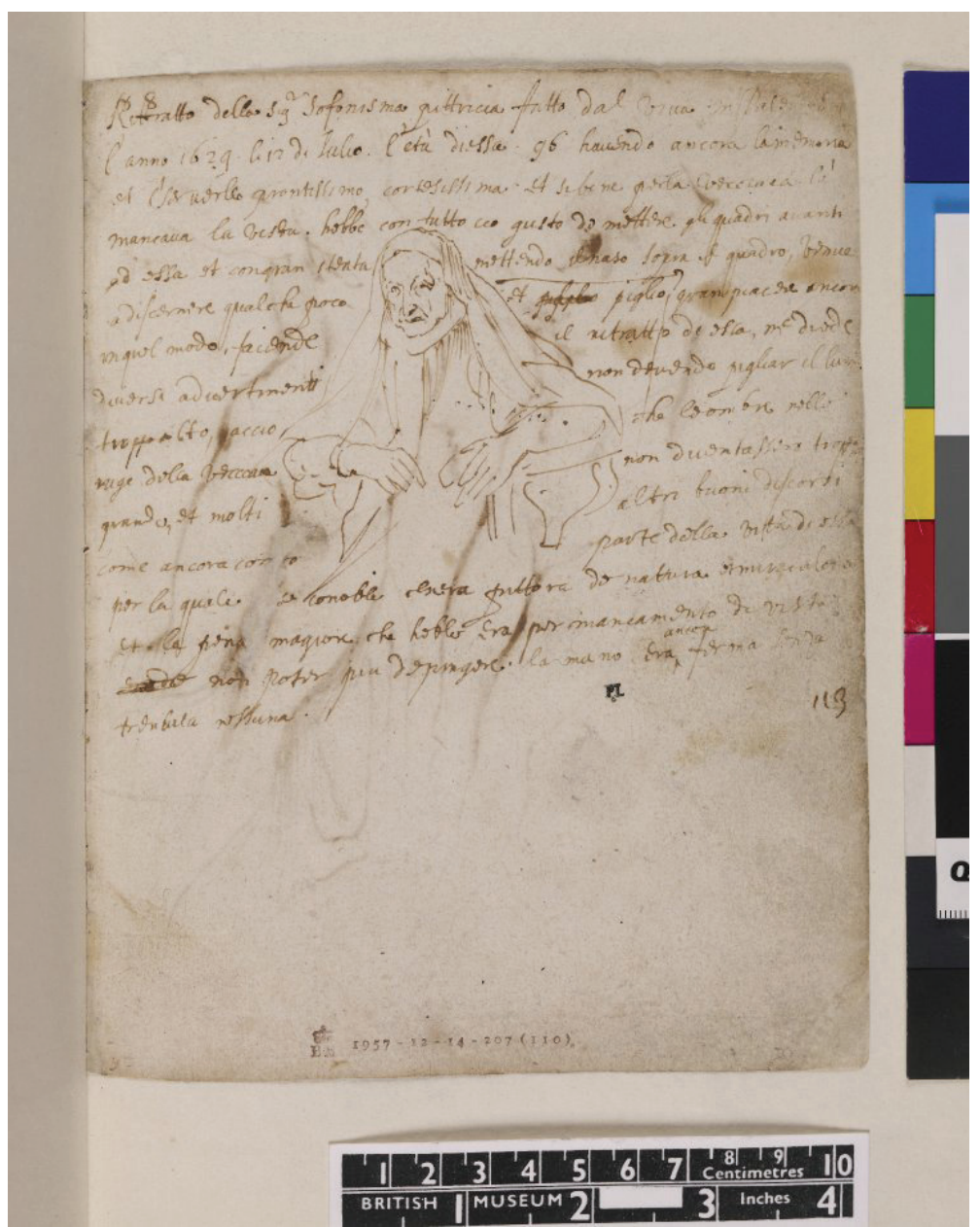

[Figura 04] Anthony van Dicky. Esboço de Sofonisba Anguissola, 1624. The British Museum, London. 

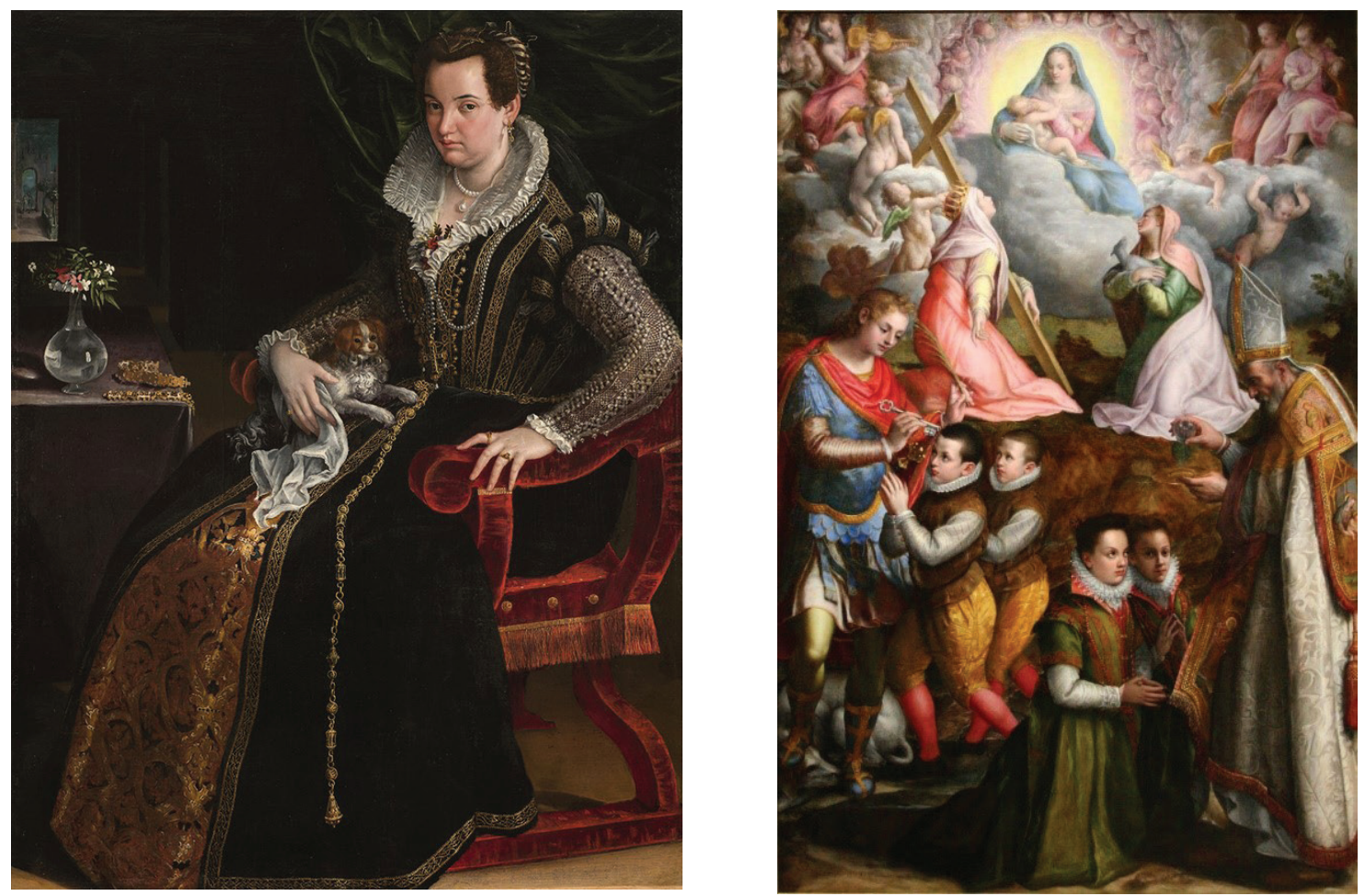

[Figura 06]

Lavinia Fontana. Consecration to the Virgin, 1599. $281 \times 185.4 \mathrm{~cm}$, Oi on canvas - Musée des Beaux-Arts, Marseille.

[Figura 05] Lavinia Fontana. Retrato de Costanza Alidosi, 1594.

$62 \times 47$, Oil on canvas - National Museum of Women in the Arts, Washington D.C.

[Figura 07] Lavinia Fontana. Minerva Dressing, 1612/1613.

$154 \times 115$ cm, Oil on canvas - Coleção Particular.

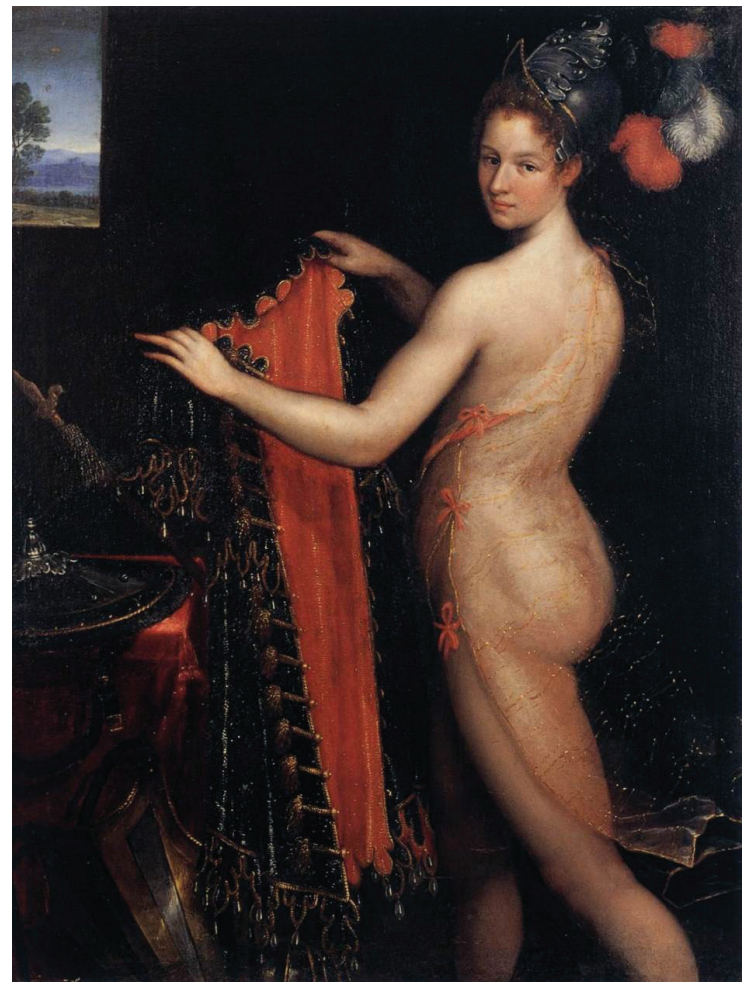

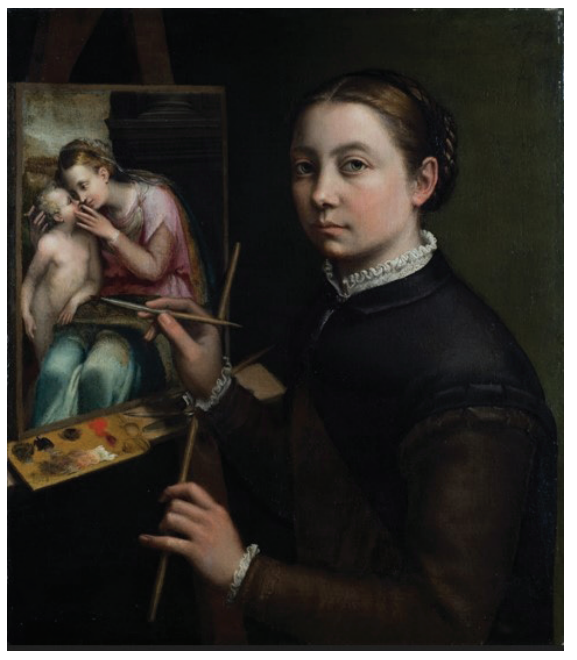

\section{[Figura 08]}

Sofonisba Anguissola. SelfPortrait at the Easel, 1556.

$26 \times 22 \mathrm{~cm}$, Oil on canvas - Muzeum-Zamek, Łańcut.

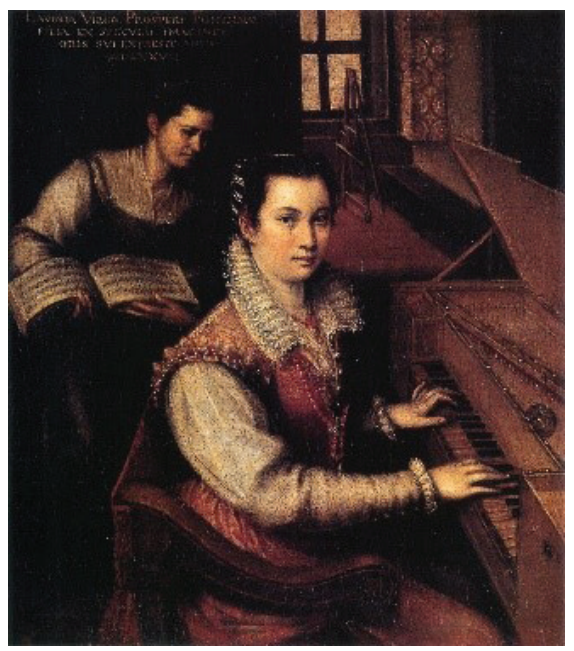

\section{[Figura 09]}

Lavinia Fontana. Self-portrait at the spinet, 1577 $27 \times 24 \mathrm{~cm}$, Oil on canvas - Accademia di San Luca Rome. 
quisas acerca do trabalho de Fontana, acredita-se que ela pode ter sido a primeira mulher a pintar nus femininos, embora não tenha como provar tal crença. Nos últimos anos em Roma, pintou duas versões de Minerva Dressing - deusa romana das artes e da sabedoria, o primeiro de 1612-13, é um nu sutil com detalhes dourados no véu utilizado nas costas e na capa vermelha e preta que segura nas mãos (figura 7).

Fontana foi a primeira mulher profissional a trabalhar na mesma esfera masculina fora de uma corte. Era católica devota, teve 11 filhos ao longo de seu casamento, porém até o fim de sua vida, apenas 4 sobreviveram. Faleceu em 1614 em Roma aos 61 anos de idade, sua produção inclui 135 obras documentadas com inúmeros retratos, pinturas religiosas e figuras mitológicas as quais recebeu encomendas de esfera pública e privada ${ }^{13}$. Suas obras se tornaram muito conhecida e prestigiada pela excelência de suas pinturas e riqueza nos detalhes.

Logo, diante do significativo debate de gênero encontrado aqui, pretende-se abrir espaço para reflexão da invisibilidade da mulher como protagonista da arte e considerar a atuação da muIher artista transformando assim, a concepção existente da historiografia na qual destaca os personagens masculinos como únicos grandes agentes e executores da História.

É importante ressaltar que o mais célebre e popular livro "A História da Arte" do escritor britânico Ernst Gombrich que trata do tema desde as pinturas pré-históricas até os dias atuais, não faz qualquer referência à uma mulher artista, bem como no livro de mesmo título da escritora brasileira, Graça Proença que cita apenas trabalhos de mulheres artistas do século passado em diante. Desta forma, através desta análise, podemos considerar que os livros de História da Arte ignoraram a produção feminina durante o longo período histórico vivido até o início do século XX, silenciando o protagonismo de artistas em diferentes áreas.

Sofonisba Anguissola e Lavinia Fontana (figuras 8 e 9), abriram espaço para outras artistas como Artemisia Gentileschi, Elisabetta Sirani, Clara Peeters e tantas outras pintoras que tiveram dificuldades em suas carreiras pelo fato de serem mulheres, porém foram amplamente reconhecidas em seu tempo. Também saliento que para o presente estudo, houve enorme dificuldade em acessar fontes, mesmo na língua inglesa. Tal obstáculo é o resultado da ausência da divulgação da conquista das mulheres nas artes visuais, principalmente anterior ao século XX.

13 HELLER, 1997 


\section{Referências Bibliográficas}

ALVES, Branca Moreira; PITANGUY, Jaqueline. O que é feminismo. São Paulo: Brasiliense, 1985. (Coleção Primeiros Passos, 20).

BURKE, Peter. O Renascimento. $1^{\text {a }}$ ed. Lisboa: Edições Texto \& Grafia, 2008.

CHADWICK, Whitney. Women, Art, and Society. $5^{\mathrm{a}}$ ed. Nova York: Thames \& Hudson world of art, 2012.

HARRIS, Ann Sutherland; NOCHLIN, Linda. Women Artists: 1550-1950. $3^{\text {a }}$ ed. Nova York: Knopf, 1984.

HELLER, Nancy. Women Artists. $3^{\text {a }}$ ed. Nova York: Abbeville Press, 1997.

KELLY-GADOL, Joan, Did Women Have a Renaissance?. In: BRIDENTHAL, Renate, KOONZ, Claudia \& STUARD, Susan, Becoming Visible. Women in European History, Boston, Houghton Mifflin, 1977, pp. 137-164.

LERNER, Gerda. A criação do patriarcado: história da opressão das mulheres pelos homens. São Paulo: Cultrix, 2019. 